\title{
Muscarinic-Dependent miR-182 and QR2 Expression Regulation in the Anterior Insula Enables Novel Taste Learning
}

\author{
Nathaniel L. Gould, ${ }^{1}$ Alina Elkobi, ${ }^{1}$ Efrat Edry, ${ }^{1,2}$ Jonathan Daume, ${ }^{1}$ and ${ }^{\circ}$ Kobi Rosenblum ${ }^{1,2}$
}

https://doi.org/10.1523/ENEURO.0067-20.2020

${ }^{1}$ Sagol Department of Neuroscience, University of Haifa, Haifa 3498838, Israel and ${ }^{2}$ Center for Gene Manipulation in the Brain, University of Haifa, Haifa 3498838, Israel

\begin{abstract}
In a similar manner to other learning paradigms, intact muscarinic acetylcholine receptor (mAChR) neurotransmission or protein synthesis regulation in the anterior insular cortex (aIC) is necessary for appetitive taste learning. Here we describe a parallel local molecular pathway, where GABA $A_{A}$ receptor control of $m A C h R$ activation causes upregulation of miRNA-182 and quinone reductase 2 (QR2) mRNA destabilization in the rodent alC. Damage to long-term memory by prevention of this process, with the use of mAChR antagonist scopolamine before novel taste learning, can be rescued by local QR2 inhibition, demonstrating that QR2 acts downstream of local muscarinic activation. Furthermore, we prove for the first time the presence of endogenous QR2 cofactors in the brain, establishing QR2 as a functional reductase there. In turn, we show that QR2 activity causes the generation of reactive oxygen species, leading to modulation in Kv2.1 redox state. QR2 expression reduction therefore is a previously unaccounted mode of mAChR-mediated inflammation reduction, and thus adds QR2 to the cadre of redox modulators in the brain. The concomitant reduction in QR2 activity during memory consolidation suggests a complementary mechanism to the well established molecular processes of this phase, by which the cortex gleans important information from general sensory stimuli. This places QR2 as a promising new target to tackle neurodegenerative inflammation and the associated impediment of novel memory formation in diseases such as Alzheimer's disease.
\end{abstract}

Key words: mAChR; miR-182; NQO2; oxidative stress; QR2; ROS

\section{Significance Statement}

Most studies on molecular mechanisms underlying memory consolidation have thus far focused on the transformation of electrical and synaptic activity to post-translation modifications, mRNA translation, and gene transcription regulation. Here, we explore a less studied mechanism of the removal of an innate constraint to allow the formation of long-term memory. Our findings point to a pathway of $\mathrm{GABA}_{\mathrm{A}}$ receptor control of mAChR activation, which causes the upregulation of miRNA-182, which can in turn lead to destabilization of QR2 mRNA in the rodent anterior insular cortex. The results propose a novel molecular cascade, complementary to the mRNA translation/transcription regulation underlying memory consolidation, by which the cortex gleans important information from general sensory stimuli.

\section{Introduction}

Animals experience a continuous stream of sensory information, which is filtered by the brain according to

Received February 25, 2020; accepted February 26, 2020; First published March 20, 2020.

The authors declare no competing financial interests. novelty (Barry et al., 2012), inter alia. Novel stimuli merit the formation of memory and identification of these stimuli in future encounters. In the case of taste stimuli, taste

Author contributions: N.L.G., J.D., and K.R. designed research; N.L.G., A.E., and J.D. performed research; E.E. contributed unpublished reagents/analytic tools; N.L.G. analyzed data; N.L.G. and K.R. wrote the paper. 
memory allows the animal to identify new safe or harmful foods and accordingly to consume or avoid them, taking into account the metabolic needs and innate preferences shaped by evolution (Katz and Sadacca, 2011; Yiannakas and Rosenblum, 2017).

Neuronal filters to detect novel information can operate immediately during information acquisition or later, during memory consolidation, when short-term memories are converted to long-term ones (Alberini and Kandel, 2014; Santini et al., 2014; Lisman et al., 2018). However, the molecular mechanisms underlying such filtering processes are unclear. Theoretically, there are two major ways to create and consolidate new internal representations of sensory information in the brain. The first, more extensively studied, involves electrical and synaptic activity, post-translation modifications, mRNA translation, and gene transcription regulation (Kandel et al., 2014). The second, less studied mechanism, involves removal of an innate constraint to allow the formation of long-term memory (Genoux et al., 2002; Rappaport et al., 2015; Gai et al., 2016).

When the mammalian cortex is presented with unfamiliar input from sensory organs, neuromodulators such as acetylcholine (ACh) induce an attuned, attentive behavior, critical to notice and remember such new information (Hasselmo and McGaughy, 2004). In the case of taste stimuli, the anterior insular cortex (alC) is the primary cortex within which reside taste representations and valence (Accolla and Carleton, 2008). Novel taste sensation induces ACh in the alC, which enables incidental taste learning to form an internal representation of the novel taste as "safe," a crucial nonassociative form of learning. ACh is released in many novel stimuli and memory formation modalities across the cortex and is a main target for cognitive enhancement in aged or demented people (Miranda et al., 2003; Pepeu and Giovannini, 2010). Following novel taste consumption, $\mathrm{GABA}_{A}$ receptors $\left(\mathrm{GABA}_{A} \mathrm{Rs}\right)$ enable local control of $A C h$ release in the alC, ensuring that only relevant gustatory events (novel taste) will cause prolonged ACh release there (Rodríguez-García and Miranda, 2016). Prolonged release of ACh in the alC is necessary for novel taste formation and stabilization. ACh has a short-term effect on neuronal activity and excitability, however, in the alC, it is released for many minutes and can also affect

This research was funded with the support of the Legacy Heritage Biomedical Science Partnership Program of the Israel Science Foundation (Grant 604/15 to K.R.). N.L.G. is a recipient of the University of Haifa President Fellowship for Excellent Students (Fellowship 501100005717).

Acknowledgments: We thank Dr. Meirav Avital-Shacham for operating the HPLC system used and providing assistance in experimental setup and data analysis. We also thank the members of the K.R. laboratory, specifically Dr. Shunit Gal-Ben-Ari, for contributions to the composition of the current research article and assistance throughout the work, and to Randa Salalha for assistance in data analysis and interpretation.

Correspondence should be addressed to Kobi Rosenblum at kobir@ psy.haifa.ac.il.

https://doi.org/10.1523/ENEURO.0067-20.2020 Copyright (C) 2020 Gould et al.

This is an open-access article distributed under the terms of the Creative Commons Attribution 4.0 International license, which permits unrestricted use, distribution and reproduction in any medium provided that the original work is properly attributed. memory consolidation (Gutiérrez et al., 2003). Here, we aimed to reveal the ACh-dependent molecular and cellular events taking place hours following experiencing novel taste in the alC and allowing the durability of a relatively weak but important form of nonassociative taste memory.

We have previously reported that novel taste memory is correlated with reduced expression of $\mathrm{N}$-ribosyl-dihydronicotinamide quinone reductase 2 (NQO2; aka QR2), which serves as a memory constraint. However, the mechanisms upstream of QR2 expression reduction and how this reduction allows the formation of incidental taste memory are unknown. Furthermore, muscarinic ACh receptor (mAChR) activation not only leads to $Q R 2$ reduced expression, but is also known to affect reactive oxygen species (ROS) clearance (Frinchi et al., 2019). Since QR2 activity can directly influence cellular ROS levels and redox state (Cassagnes et al., 2018), it is unclear whether some of the anti-inflammatory effect of $\mathrm{mAChR}$ activation is mediated by QR2 suppression. If so, redox modulation via $m A C h R$-dependent $Q R 2$ downregulation hours after novel taste consumption might affect redox-sensitive molecules within the cell, altering the neuronal intrinsic properties. As redox also plays an important role in learning and memory (Massaad and Klann, 2011) and is proposed to underlie many neurodegenerative diseases, it is therefore important to define the links among novel taste sensation, ACh, QR2, and their function in the alC. Here, we first identify the sequential molecular events taking place in the alC from local control of ACh release to reduced QR2 expression and suggest a possible function of QR2 in the brain.

\section{Materials and Methods}

\section{Subjects}

Animals used were 225-250 g male Sprague Dawley rats and 8-week-old, 20-25 g C57BL/6 (Envigo) male mice. The animals were kept in the animal core facilities at the University of Haifa, in a temperature-controlled environment $\left(22-24^{\circ} \mathrm{C}\right)$, with a $12 \mathrm{~h}$ light/dark cycle (light phase, 7:00 A.M. to 7:00 P.M.). Water and rodent chow were provided ad libitum. All experiments were approved by the University of Haifa Animal Care and Use committee (license numbers 437/16, 487/17, 488/17, and 557/18). Animals were given $7 \mathrm{~d}$ of acclimatization before experimentation, and during the entire period animals were handled in accordance with University of Haifa practices and standards, in compliance with the National Institutes of Health guidelines for the ethical treatment of animals.

\section{Animal behavior}

Animals were taught to drink water from pipettes filled with water (two $10 \mathrm{ml}$ pipettes for rats and one $2 \mathrm{ml}$ pipette for mice) once a day for $20 \mathrm{~min}$, for 3 (rats) to 5 (mice) days. The following day, animals were given pipettes containing a novel taste (saccharin $0.1 \%$ for rats and $0.5 \%$ for mice; $\mathrm{NaCl} 0.3 \%$ for rats and $0.5 \%$ for mice). For QR2 mRNA quantification, animals were killed $3 \mathrm{~h}$ later. For novel taste learning in rats, long-term memory of the taste was assessed the day after the first consumption of the 
novel taste by a choice test between two pipettes containing water and two containing the novel taste. In mice, the day after novel taste consumption, the animals were given water in pipettes again. Then, $48 \mathrm{~h}$ after novel taste consumption, they were given a choice between one pipette of water and another of the novel taste. Memory, as determined by the choice test given to rats and mice, was measured by calculating a preference index for the novel taste. This was done by dividing the volume of novel taste by the total volume consumed - [novel taste/(novel taste + water)] $* 100$ (Rosenblum et al., 1993). Statistical analysis was performed using GraphPad Prism 7 software (GraphPad Software).

\section{Pharmacology \\ Materials}

Pharmacological agents were diluted or dissolved in $0.9 \%$ saline, prepared by dissolving $\mathrm{NaCl}$ (Sigma-Aldrich) in double-distilled water (DDW). Reagents that first required dissolving in DMSO were used with vehicle containing the saline solution with DMSO diluted to a concentration equal to that of the reagent. In this manner, S29434 (synthesized by the Nancy and Stephen Grand Israel National Center for Personalized Medicine, Weizmann Institute of Science, Rehovot, Israel) $8 \mathrm{mg} / \mathrm{kg}$ in $4 \%$ DMSO and scopolamine (Sigma-Aldrich) $2 \mathrm{mg} / \mathrm{kg}$ and were applied to animals by intraperitoneal injection.

\section{Microinjections}

Rats were anesthetized with $0.3 \mathrm{ml} / 100 \mathrm{~g}$ body weight Equithesin [2.12\% $\mathrm{MgSO}_{4}, 10 \%$ ethanol, 39.1\% 1,2-propanolol, $0.98 \%$ sodium pentobarbital, and $4.2 \%$ chloral hydrate (all from Sigma-Aldrich); Merhav and Rosenblum, 2008; Stern et al., 2013]. They were then placed in a stereotaxic device (Stoelting) and implanted bilaterally with 10 $\mathrm{mm}, 23$ gauge steel guide cannulas over the IC [coordinates relative to bregma: anteroposterior (AP) $1.2 \mathrm{~mm}$; mediolateral (ML) $\pm 5.5 \mathrm{~mm}$; dorsoventral (DV) $5.5 \mathrm{~mm}$; Paxinos and Watson, 2007]. Cannulas were fixed with acrylic dental cement and two screws. Rats were then given a week to recover before undergoing any further experimentation.

Following the recovery period, animals began behavioral training as has been described. For microinjections $20 \mathrm{~min}$ before taste learning, the stylus within the guide cannulas was removed, and a 28 gauge injection cannula was inserted $0.5 \mathrm{~mm}$ beyond the tip of the guide cannula. This was connected to a Hamilton microsyringe via PE20 tubing, and $0.5-1 \mu \mathrm{l}$ of vehicle or agent was injected [vehicle: $0.07 \mu \mathrm{g}$ bicuculline, $0.07 \mu \mathrm{g}$ muscimol (both from Tocris Bioscience), $1 \mu \mathrm{g}$ Eserine (Sigma-Aldrich), and $13 \mathrm{ng}$ S29434 in 0.08\% DMSO] at $0.5 \mu \mathrm{l} / \mathrm{min}$. The injection cannula was then kept for a further minute before removal to minimize retraction, prevent displacement of reagents from the injection area, and allow time for the solubilized agents to dissipate into the tissue.

\section{Viral vectors and infection}

Recombinant lentiviral vector production

Self-inactivating, third-generation HIV-1-based viral vectors were produced by transient cotransfection of four endotoxin-free plasmids (Endo Free Plasmid Maxi Kit, catalog \#12362, Qiagen) in Invitrogen Human Embryonic Kidney 293FT (HEK293FT; Thermo Fisher Scientific) cells (Tiscornia et al., 2006). Transfer plasmids pLenti-miR182GFP and pLenti-control-GFP, as well as short hairpin RNA (shRNA) constructs targeting QR2 and scrambled control (Rappaport et al., 2015) were purchased from Applied Biological Materials. Cells were cultured in Invitrogen DMEM with 10\% fetal bovine serum (Thermo Fisher Scientific), penicillin (100 IU/ml), and streptomycin $(100 \mathrm{mg} / \mathrm{ml})$, and were kept in a $37^{\circ} \mathrm{C}$ incubator with $5 \%$ $\mathrm{CO}_{2}$. Transfection was performed using PEI (SignaGen), according to manufacturer instructions. Medium was changed 30 min before transfection and, following a $17 \mathrm{~h}$ incubation, the medium was replaced with DMEM supplemented with $10 \%$ fetal bovine serum. At $48 \mathrm{~h}$ post-transfection, medium was harvested, cleared by low-speed centrifugation (800 RCF, $10 \mathrm{~min}, 4^{\circ} \mathrm{C}$ ), and filtered using $0.45 \mu \mathrm{m}$ pore filters (Nunc). Vectors were then concentrated by ultracentrifugation using the SW28 rotor (Beckman Coulter; $19,000 \mathrm{rpm}, 2.5 \mathrm{~h}, 15^{\circ} \mathrm{C}$ ), and the pellets obtained were finally suspended in HBSS (SigmaAldrich) and stored at $-80^{\circ} \mathrm{C}$. Vectors were titrated by transduction of HEK293FT cells using serial dilutions of the viral vector stock, along with $8 \mu \mathrm{g} / \mu \mathrm{l}$ Polybrene (Sigma-Aldrich), and GFP expression was analyzed by flow cytometry analysis $2 \mathrm{~d}$ later. The lentiviral titer obtained was 108 transducing units $/ \mathrm{ml}$.

\section{Surgeries and injection}

Mice were anesthetized with ketamine and Domitor (0.5 mg/kg, i.p., each) and were given Norocarp $0.5 \mathrm{mg} / \mathrm{kg}$ (i.p.). After $40 \mathrm{~min}$, the mice were placed in a robotic stereotaxic device (NeuroStar). The scalp was cut centrally along the length of the skull, to expose the bregma and $\lambda$. Using bregma and $\lambda$ as reference points for the drilling and injection site (coordinates for alC relative to bregma: AP $0.86 \mathrm{~mm}, \mathrm{ML} \pm 3.4 \mathrm{~mm}$, DV $4 \mathrm{~mm}$ ), $0.8 \mu$ of virus was injected at a rate of $0.05 \mu \mathrm{l} / \mathrm{min}$ using StereoDrive and InjectoMate software (NeuroStar). Before injection, the syringe (Hamilton) was kept motionless in the injection site for $5 \mathrm{~min}$. Following the injection, the syringe was left motionless in the injection site for a further $10 \mathrm{~min}$ to minimize retraction. Animals were given a week to recover, and a further week to a month to ensure full viral expression before any further experimentation.

\section{Brain dissection and tissue preparation}

Mice were killed by cervical dislocation, and brains were immediately removed and flash frozen on a tin foil platform floated on liquid nitrogen. Brains were kept in $-80^{\circ} \mathrm{C}$, and eventually were transferred to a Leica $\mathrm{CM}$ 1950 Cryostat and equilibrated to $-15^{\circ} \mathrm{C}$. For quantitative PCR, samples were dissected from a 1-mm-thick coronal slice (starting at bregma: AP, $1.18 \mathrm{~mm}$; ML, $\pm 3 \mathrm{~mm}$; DV, $3.6 \mathrm{~mm}$; ending at bregma: $\mathrm{AP}, 0.14 \mathrm{~mm}$; $\mathrm{ML}, \pm 3.6 \mathrm{~mm}$; DV, $4.1 \mathrm{~mm}$; Franklin and Paxinos, 2008) using a tissuepunching device. Rats were killed by guillotine, brains were immediately removed, and the IC was dissected directly, using the medial cerebral artery and rhinal fissure as place markers. With both animals and dissection 
methods, samples were finally placed in $1.5 \mathrm{ml}$ tubes and kept at $80^{\circ} \mathrm{C}$ until further processing. For the isolation of small molecules from mouse brain cytoplasm, brains were immediately placed on ice following sacrifice. The cortices were removed and mechanically homogenized with a teflon pestle homogenizer, in $1 \mathrm{ml}$ reaction buffer (50 mM Tris, $150 \mathrm{mM} \mathrm{NaCl}$, adjusted to $\mathrm{pH} 8.5$ with $\mathrm{HCl}$ ). The lysed samples were then centrifuged for $10 \mathrm{~min}$ at $1,000 \mathrm{RCF}$, and the supernatant was placed into Amicon Ultra $2 \mathrm{ml}$ Ultracel $3 \mathrm{~K}$ (Merck) centrifugal filters. Small molecule filtrate was then collected following a $1 \mathrm{~h}$ centrifugation of the samples through the centrifugal filters at 4,000 RCF in a swinging bucket rotor centrifuge.

\section{Western blot}

Kv2.1 oligomerization was measured as previously described in the study by Cotella et al. (2012). Tissue samples were homogenized in nonreducing lysis buffer (HEPES $10 \mathrm{~mm}$, EGTA 2 mm, EDTA $2 \mathrm{~mm}, 1 \times$ phosphatase inhibitor cocktail 3 , and $1 \times$ protease inhibitor cocktail; all from Sigma-Aldrich). Protein content was measured using the BCA Protein Assay Kit (GE Healthcare). Samples were diluted in $2 \times$ sample buffer containing $4 \%$ SDS to $1 \mu \mathrm{g}$ protein $/ 1 \mu$ l. No $\beta$-mercaptoethanol was added to samples used to measure cysteine oxidation-dependent clumping. Samples were briefly vortexed, and $10 \mu \mathrm{l}$ was loaded in precast 4-20\% Mini-PROTEAN TGX Stain Free Gels (Bio-Rad). Samples were transferred to PVDF membranes, washed three times in TBST, blocked for $2 \mathrm{~h}$ in blocking buffer (Bio-Rad), and exposed to a mouse monoclonal KV2.1 antibody (1:500; UC Davis/NIH NeuroMab) overnight. After three further washes in TBST, membranes were incubated with anti-mouse HRP-conjugated secondary antibodies at room temperature for $1 \mathrm{~h}(1: 10,000$; Millipore Bioscience Research Reagents) and washed a further three times. Immunoblotting was conducted using the Westar Supernova Kit (Cyanagen), images were acquired with a CCD camera, and analysis was done using Quantity One software (Bio-Rad). KV2.1 clumping was calculated by the ratio of oligomeric $(\sim 200 \mathrm{kDa})$ to monomeric $(\sim 100 \mathrm{kDa})$ bands seen, as previously described (Cotella et al., 2012). Statistical analysis was performed using Graph Pad Prism 7 software.

\section{RNA extraction, reverse transcription, and qPCR RNA extraction}

TRI Reagent ( $300 \mu \mathrm{l} / 1 \mathrm{~mm}^{3}$ sample) was added directly to excised brain tissue, on ice. Samples were homogenized and transferred to $1.5 \mathrm{ml}$ tubes, and 1-bromo-3chloropropane was then added at one-tenth of the volume of TRI Reagent and mixed thoroughly. Following phase separation by chilled $\left(4^{\circ} \mathrm{C}\right)$ centrifugation for $15 \mathrm{~min}$ at 12,000 RCF, 2-propanol was added in equal volume to the RNA phase taken, in new tubes. After a 30 min chilled centrifugation at $12,000 \mathrm{RCF}$, the pelleted RNA was washed with $300 \mu \mathrm{l}$ ice-cold $75 \%$ ethanol. A final chilled centrifugation for $10 \mathrm{~min}$ at $7600 \mathrm{RCF}$ followed, and the resultant pellet was air dried and eluted in $30 \mu \mathrm{l}$ of ultrapure water (Biological Industries). All reagents used were purchased from Sigma-Aldrich, unless otherwise stated.

\section{Reverse transcription and $q P C R$}

RNA was reverse transcribed to cDNA using the Applied Biosystems (Thermo Fisher Scientific) High Capacity cDNA Reverse Transcription (RT) kit. To obtain QR2 pre-mRNA, the RT kit random primers were replaced with a QR2 Exon 6/Intron 6 targeting primer (primer sequence: CATTTAATCGAGAGGAAAGG), as well as a reference HPRT mRNA primer (exon 8 targeting primer sequence: CCCTGAAGTACTCATTATAG). Before RT with these specific primers, the RNA was treated with DNase I (AMPD1-1KT, Sigma-Aldrich) to prevent nonspecific Serpin 6a amplification from the QR2 primer during qPCR. To verify that no genomic QR2 or HPRT was being measured, one sample from each group underwent RT without reverse transcriptase. The resultant cDNA was then used in TaqMan (Thermo Fisher Scientific) gene expression assays.

TaqMan primers used were QR2 (human, Hs01056948_ m1; mouse, Mm01332867_m1; and rat, Rn01434728_g1), which were normalized to GAPDH (mouse, Mm99999915 g1; human, Hs99999905_m1; and rat, Rn99999916_s1) or HPRT (mouse, Mm00446968_m1). For miRNA-182 (miR182), TaqMan MicroRNA kit was used (002599) and was quantified against U6 (001973). Relative quantitation was performed by calculating $\Delta \Delta \mathrm{Ct}$ of the target genes. Statistical analysis was performed using GraphPad Prism 7 software.

\section{Activity assays}

Reverse-phase HPLC profile of QR2 activity assay

QR2-dependent production of menadiol was measured as previously described (Boutin et al., 2005), with modifications. Cytoplasmic small molecules (CSMs), collected as described above, were applied to an Acquity Ultra High Performance LC (Waters), and $10 \mu$ of the samples were injected into a Spherisorb $5 \mathrm{~mm}$ C8 Analytical Column (Waters). The elution system consisted of a linear $30-85 \%$ acetonitrile gradient in $0.1 \%$ aqueous formic acid over $9 \mathrm{~min}$ (flow rate, $1 \mathrm{ml} / \mathrm{min}$ ), while absorption at $280 \mathrm{~nm}$ was measured. Menadione $1 \mathrm{~mm}$ either alone or with QR2 500 nm (both from Sigma-Aldrich) was added to the CSMs, and was similarly run. An increase in menadiol product formation was measured every $10 \mathrm{~min}$ at the 8.5 min mark of each of five injections. S29434 was added in increasing doses $(62.5,125,250$, and $500 \mathrm{~nm})$, and changes in the rate and amplitude of menadiol formation were measured. Menadiol concentrations were measured by the area under the curve of peak formation, using Empower 2 software (Waters).

\section{QR2 and NQO1 activity assay}

QR2 or NQO1 (Sigma-Aldrich) assays were conducted in $50 \mathrm{~mm}$ Tris, $150 \mathrm{~mm} \mathrm{NaCl}$ buffer adjusted to $\mathrm{pH} 8.5$ with $\mathrm{HCl}$. To $100 \mu \mathrm{l}$ reactions in a black-walled, clear bottom, 96-well plate (Thermo Fisher Scientific), QR2 or NQO1 enzyme (10 nM) was added, along with both BNAH (1-benzyl-1,4-dihydronicotinamide; Tocris Bioscience) and menadione $100 \mu \mathrm{m}$. The fluorescence of BNAH was monitored every $30 \mathrm{~s}$ by excitation with $340 \mathrm{~nm}$ and emission at $440 \mathrm{~nm}$ using a Tecan Infinite M200 PRO fluorescence microplate reader. To validate inhibitor efficacy and 
enzymatic activity, either S29434 (200 nM) or dicoumarol $(200 \mu \mathrm{M})$ was added to the reaction. Each condition was done with or without enzyme, the initial linear phase of enzymatic activity was measured, and the nonenzymatic BNAH signal decay was subtracted from each relevant enzymatic reaction.

\section{Brain lysate quinone reductase activity assay}

Brains were briefly removed from 3- to 4-month-old $\mathrm{C} 57 \mathrm{BL} / 6$ mice and placed on ice. The cortices were dissected and homogenized using a glass-Teflon homogenizer in $5 \mu \mathrm{l} / \mathrm{mg}$ tissue with $50 \mathrm{~mm}$ Tris and $150 \mathrm{~mm} \mathrm{NaCl}$ buffer adjusted to $\mathrm{pH} 8.5$ with $\mathrm{HCl}$ and containing $1 \mathrm{~mm} n$ octyl-B-D-glucopyranoside. Samples were then centrifuged at $4^{\circ} \mathrm{C}$ for $5 \mathrm{~min}$ at $12,000 \mathrm{RCF}$, and the supernatant was kept. Each sample used for the activity assay was loaded into a 96-well, clear flat-bottomed plate (Thermo Fisher Scientific) at a final volume of $100 \mu \mathrm{l}$, with $100 \mu \mathrm{M}$ BNAH either with or without 200 nm of S29434. The fluorescence of BNAH was monitored every $30 \mathrm{~s}$ by excitation with $340 \mathrm{~nm}$ and emission at $440 \mathrm{~nm}$ using a Tecan Infinite M200 PRO fluorescence microplate reader, and the initial linear phase of the reaction was measured.

\section{Cell-based ROS assay}

HEK293FT cells were cultured in Invitrogen DMEM (Thermo Fisher Scientific) supplemented with fetal bovine serum (final concentration, 10\%), penicillin-streptomycin antibiotics, and L-glutamine. Cells were grown in $100 \mathrm{~mm}$ plates until $80-90 \%$ confluence and were passaged every 2-3d. For cellular ROS detection, cells were collected, centrifuged, and resuspended in fresh Minimum Essential Medium without phenol red. A total of 50,000 cells/well were seeded on poly-L-lysine-coated Nunc black, 96well, clear flat-bottomed plates (Thermo Fisher Scientific) and left to adhere for $3 \mathrm{~h}$.

The DCFDA $\left(2^{\prime}, 7^{\prime}\right.$-dichlorofluorescin diacetate) ROS detection kit (Abcam) protocol was then followed. Briefly, cells were incubated with $20 \mu \mathrm{m}$ DCFDA for $45 \mathrm{~min}$ in the dark at $37^{\circ} \mathrm{C}$, and then treated with DMSO, S29434 and ascorbic acid. The QR2 inhibitor S29434 was dissolved in DMSO to $20 \mathrm{~mm}$ and Ascorbic Acid (Sigma-Aldrich) was solubilized in DDW to $55 \mathrm{~mm}$. Both were subsequently diluted using the provided buffer from the Abcam kit (S29434 and ascorbic acid final concentrations, $20 \mu \mathrm{m}$ and $5 \mathrm{~mm}$, respectively), supplemented with $10 \%$ fetal bovine serum. In all treatments, DMSO was present in equal concentration of $0.1 \%$. The cells were incubated for a further $4 \mathrm{~h}$ with the different treatments in the dark at $37^{\circ} \mathrm{C}$. ROS was measured using a Tecan Infinite M200 PRO fluorescence microplate reader, with excitation/emission of $485 / 535 \mathrm{~nm}$. Statistical analysis was performed using GraphPad Prism 7 software.

\section{Statistical analysis}

Data collected were tested for normality using ShapiroWilk and Kolmogorov-Smirnov normality tests, when not transformed/normalized. All normally distributed data were analyzed using Student's $t$ test, one-way ANOVA, two-way ANOVA, or two-way repeated-measures ANOVA, followed by Tukey's post hoc analysis. For data not normally distributed, or data that first required normalization before analysis (e.g., when combining separate sets of experimental data for Western blot analysis), nonparametric Mann-Whitney test, or Kruskal-Wallis test followed by Dunn's multiple-comparisons test were used. All data are presented as the mean \pm SEM. All descriptive statistics, normality tests, and parametric and nonparametric tests were conducted using GraphPad Prism 7 (GraphPad Software) and SPSS 25 (IBM) software.

\section{Data availability}

All statistical analyses are available in Extended Data Table 1: Detailed Statistical Analysis.

\section{Results}

\section{QR2 inhibition in the alC rescues scopolamine- induced amnesia}

We have previously shown that novel taste consumption reduces mRNA levels of QR2 in the rat alC (Rappaport et al., 2015). To repeat and expand this finding to other species, we extended our research to mice, where more genetic tools are readily available. We therefore measured mRNA levels of QR2 in the alC in both rats and mice following novel taste consumption (Fig. 1a). In agreement with Rappaport et al. (2015), $3 \mathrm{~h}$ following novel taste consumption QR2 mRNA was significantly reduced in the alC of both rats and mice (Fig. 1b,c), but not in other non-taste-related brain regions (Extended Data Fig. 1-1). To test whether, as in rats, reducing QR2 expression in the mouse alC would also result in improved novel taste memory, a lentivirus harboring shRNA targeting QR2 (shQR2) was made, as well as a scrambled control (Extended Data Fig. 1-2). Following stereotaxic injection of the virus into the alC, mice were given a week to recover and then were taught to drink water from pipettes. The mice were then given saccharin $(0.5 \%)$ and, on the following day, water once again. A day later, the mice were given both water and saccharin in pipettes, and preference for the novel taste (saccharin) was measured (Fig. 1d). Mice expressing shQR2 drank significantly more saccharin than the animals injected with a scrambled control (Fig. 1e) and showed significantly reduced levels of QR2 mRNA (Fig. 1f) in alC only (Extended Data Fig. 1-2). Hence, in mice, as in rats, reduction of QR2 expression in the alC results in improved novel taste memory.

Functionally, systemic inhibition of QR2 with a smallmolecule inhibitor (S29434) results in enhanced novel taste memory. To test whether this effect of external reduction of QR2 activity is dependent specifically on the alC, we stereotaxically injected S29434 (13 ng; see Materials and Methods) or vehicle into the rat alC (Fig. $1 \mathrm{~g})$ either $20 \mathrm{~min}$ before novel taste consumption $(0.1 \%$ saccharin) or $5 \mathrm{~min}$ afterward, and tested taste preference the following day (Fig. $1 h$ ). Since rats share the same QR2 effects with mice, we opted for the larger rodent to conduct implantations to reduce relative damage to the brain and to ease correct cannula insertion (by virtue of a larger alC). Rats injected with S29434 either before or after novel taste consumption demonstrated 
a

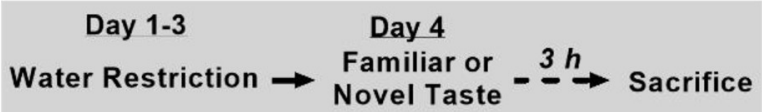

b

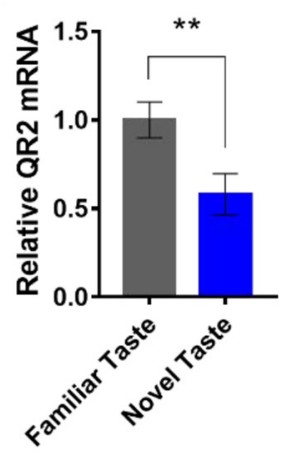

C

Mouse IC

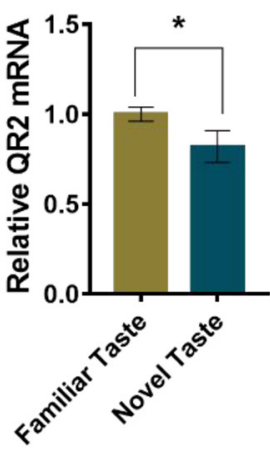

d

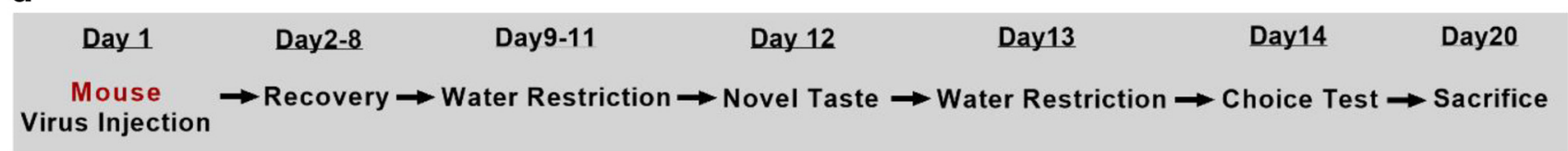

e

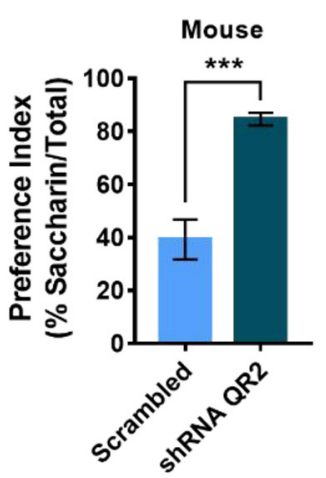

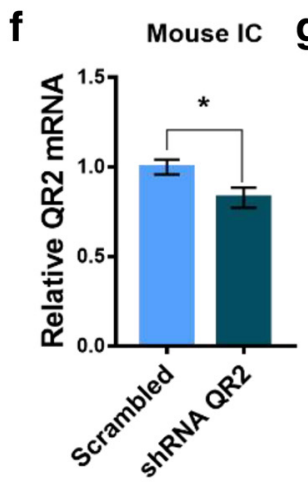

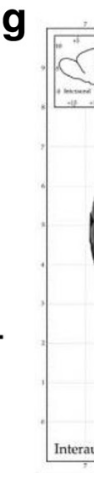

Rat

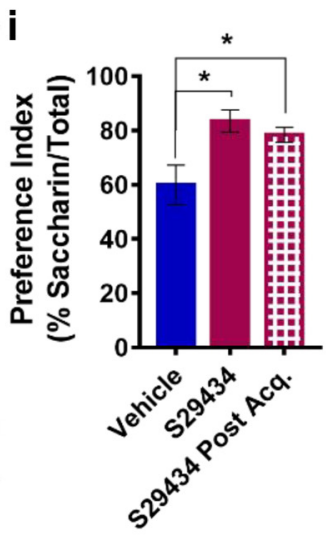

h
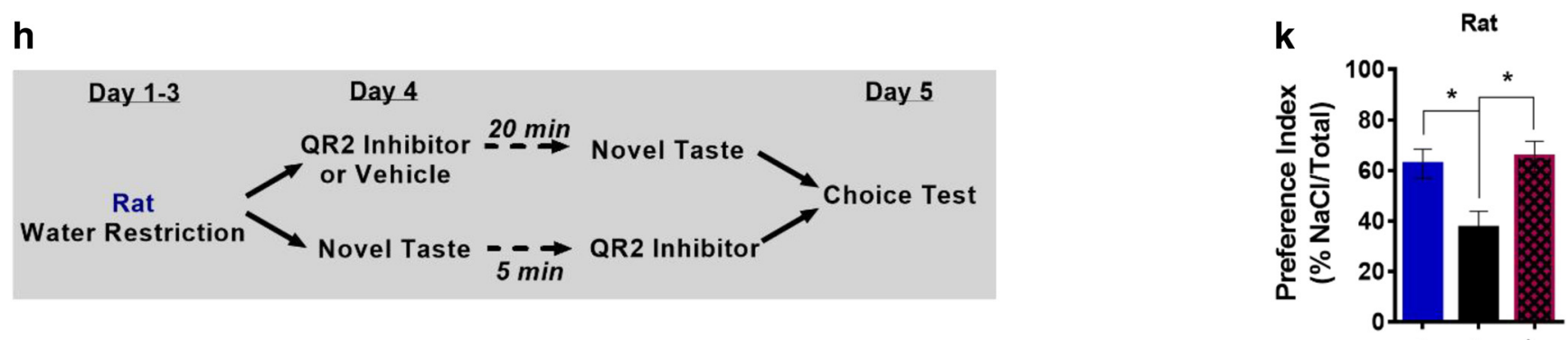

j
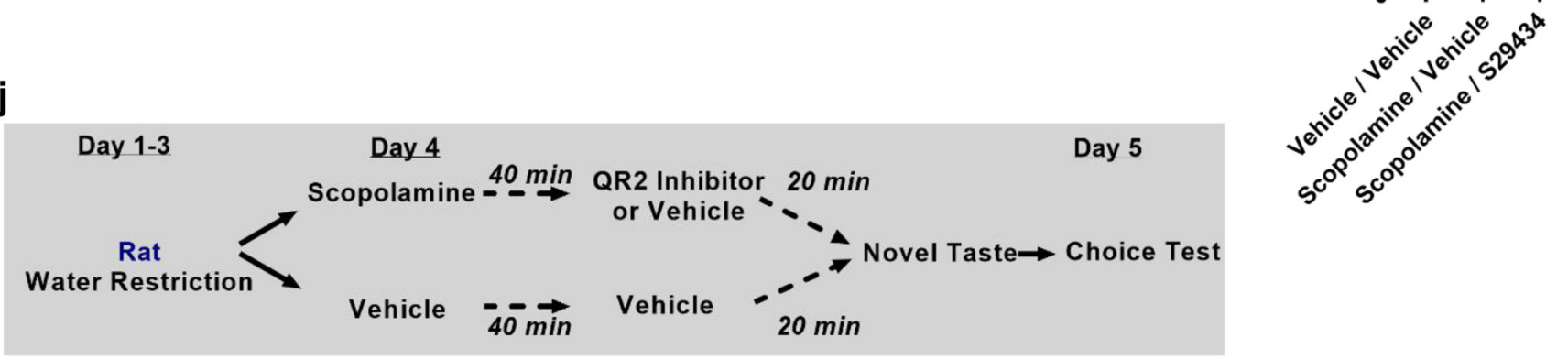

Figure 1. QR2 inhibition in the alC rescues scopolamine-induced amnesia. a, Rats were given a novel or familiar taste and killed $3 \mathrm{~h}$ later. $\boldsymbol{b}, \mathrm{A}$ significant reduction in QR2 mRNA was measured in the alC of rats following novel taste. $\boldsymbol{c}$, QR2 mRNA expression was significantly reduced in the alC of mice following novel taste. $\boldsymbol{d}$, Mice injected with shQR2 or scrambled lentivirus to the alC 
continued

underwent novel taste learning, and $2 \mathrm{~d}$ later they were given a choice test and preference was assessed. e, Mice injected to the alC with shQR2 showed significantly improved novel taste memory compared with controls. $f$, Mice injected to the alC with shQR2 showed significantly reduced QR2 mRNA levels compared with controls. g, Cannula position validation following behavioral tests. $\boldsymbol{h}$, Rats were given a novel taste after receiving an intracranial infusion of vehicle or S29434 20 min prior, or received a novel taste and then received S29434 $5 \mathrm{~min}$ later. The next day, the preference for the novel taste was measured. $\boldsymbol{i}$, S29434-mediated inhibition of QR2 significantly improved novel taste memory, whether given before or after novel taste presentation. $\boldsymbol{j}$, Rats were given a novel taste after having first received an intracranial infusion of vehicle or S29434 20 min prior and an intraperitoneal injection of vehicle or scopolamine $1 \mathrm{~h}$ before. The following day taste memory was tested. $\boldsymbol{k}$, Scopolamine significantly impedes novel taste memory, while S29434 prevents scopolamine-induced memory deficit. Data are shown as the mean \pm SEM. $* p<0.05 ; * * p<0.01$; $* * * p<0.001$. See supporting data in Extended Data Figure 1-1 and Extended Data Figure 1-2.

significantly greater consumption of saccharin a day later, indicating a stronger memory of the novel and safe taste experienced the previous day (Fig. 1i). Moreover, the enhanced incidental taste learning after inhibition of QR2 and the reduction in QR2 mRNA levels hours following novel taste experience are indicative of QR2 involvement in memory consolidation.

Reduced expression of QR2 in the alC following the consumption of novel taste is mAChR dependent (Rappaport et al., 2015). To test whether the reduction in QR2 mRNA levels is downstream of the effect of mAChR on novel taste memory, we injected rats with either the $\mathrm{mAChR}$ antagonist scopolamine (2 mg/kg, i.p.) or vehicle 40 min before stereotaxic administration of S29434 or vehicle in the alC. After $20 \mathrm{~min}$, the animals were subjected to the novel taste learning paradigm (Fig. $1 j$ ). Since taste novelty, but not the taste itself, was shown to affect QR2 in the study by Rappaport et al. (2015), $\mathrm{NaCl}(0.3 \%)$ was used instead of saccharin to assess the generalizability of the effect of novelty on QR2 across different tastes. Scopolamine significantly reduced novel taste memory by $25 \%$ compared with controls, while S29434 rescued this amnesic phenotype (Fig. 1k). These results suggest that QR2 is reduced across species in the rodent alC and is a new addition to the currently known downstream targets of $\mathrm{mAChR}$ activation during novel taste memory formation.

\section{Local GABA $A$ receptor activity in the alC is upstream of muscarinic AChR-dependent reduction in QR2 mRNA levels following novel taste experience}

QR2 expression reduction following novel taste consumption is found only locally, within the alC. We therefore aimed to establish how QR2 expression reduction is contained only within the relevant brain area necessary for the long-term storage of taste memory. GABA $A_{A}$ Rs tonically control local ACh release in the alC from distal nucleus basalis magnocellularis cholinergic neurons, enabling ACh influx into the alC during novel, but not familiar, taste consumption (Rodríguez-García and Miranda, 2016). We hypothesized that the mAChR-dependent reduction in QR2 mRNA levels in the alC following novel taste consumption is regulated by the local $\mathrm{GABA}_{A} R$ disinhibitory circuit. To test this hypothesis, we stereotaxically injected bicuculline $\left(G A B A_{A} R\right.$ antagonist, $\left.0.07 \mu \mathrm{g}\right)$, muscimol (GABA $R$ agonist, $0.07 \mu \mathrm{g})$, or vehicle into the rat alC 20 min before consumption of either a familiar or novel taste, and the rats were killed $3 \mathrm{~h}$ later (saccharin; Fig. 2a). Consumption of a novel taste reduced QR2
mRNA levels compared with a familiar taste (water) in the control groups receiving vehicle (Fig. 2b). However, bicuculline caused a reduction in QR2 expression regardless of taste novelty/familiarity, while muscimol prevented the reduction in QR2 mRNA levels following novel taste consumption. Notably, however, muscimol did hold QR2 expression in an intermediate level, nonsignificantly reduced compared with controls. No change in QR2 expression was measured in a control cortex, the occipital cortex (OC), of these animals (Extended Data Fig. 2-1).

To verify that bicuculline induced reduction in QR2 mRNA levels following familiar taste consumption was due to subsequent $\mathrm{mAChR}$ activation, rats were given scopolamine or vehicle $40 \mathrm{~min}$ before stereotaxic administration of bicuculline into the alC (Fig. 2c,d). Scopolamine injection before bicuculline microinfusion prevented the $\mathrm{GABA}_{\mathrm{A}} \mathrm{R}$ dependent reduction in QR2 mRNA expression in the alC (Fig. 2e). The OC did not show any change in QR2 expression (Extended Data Fig. 2-1). Next, we hypothesized that stereotaxic administration of bicuculline into the alC would also improve novel taste memory. To test this hypothesis, rats were stereotaxically injected with bicuculline or vehicle into the alC and were given saccharin 20 min later. The following day, novel taste memory was measured by preference index (Fig. 2f). The group that received bicuculline showed enhanced memory, having a significantly increased preference for saccharin (Fig. 2g). These results suggest that a local $\mathrm{GABA}_{A} \mathrm{R}$-dependent release of $A C h$ in the alC following novel taste consumption activates $\mathrm{mAChR}$, which causes a reduction in QR2 and allows the formation of incidental taste memory.

\section{miR-182 is upregulated locally in the alC following novel taste consumption in a GABA $A_{A} R$-mediated, muscarinic AChR-dependent manner}

Since QR2 pre-mRNA was not altered following novel taste consumption (Fig. 3a), an open question remained as to how novelty reduces QR2 mRNA in the alC. One possible mechanism is the destabilization of QR2 mRNA by miR. Some miRs have been shown to play an important role in memory formation (Woldemichael and Mansuy, 2016); therefore, we selected 15 prime miR candidates and measured their expression directly 1 and $3 \mathrm{~h}$ following novel or familiar taste consumption. Of these, miR-182 was elevated $1 \mathrm{~h}$ following novel taste consumption in the alC of mice (Fig. 3b). 
a
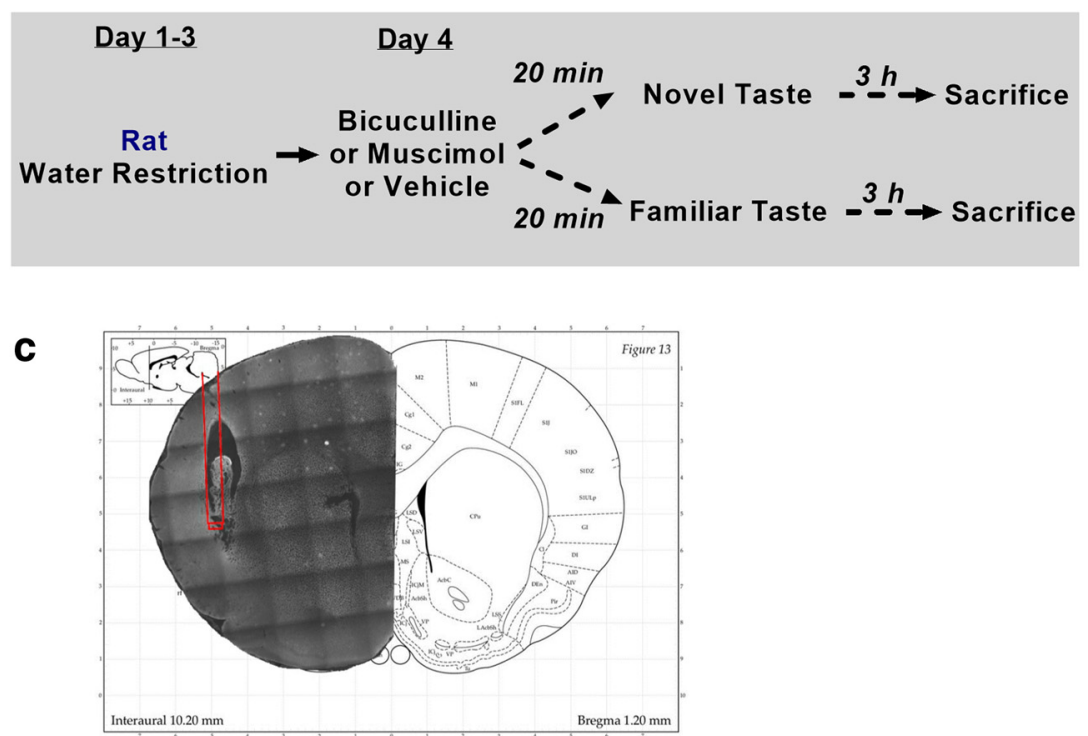

d

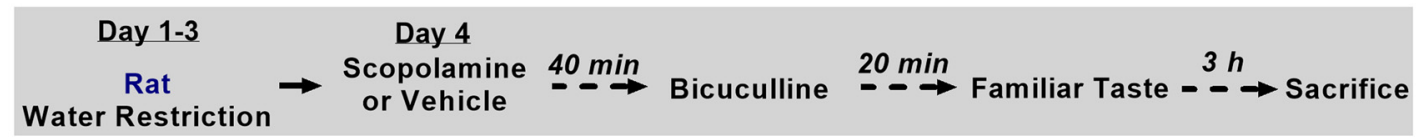

b

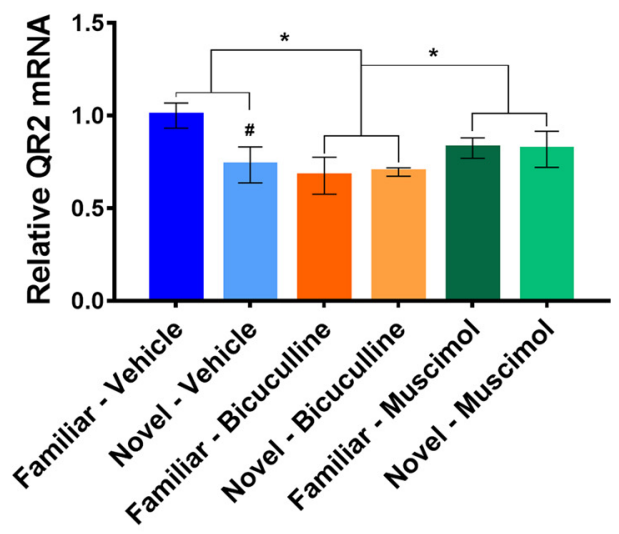

f

$\underset{\text { Water Restriction }}{\operatorname{\text {Ray}1-3}} \rightarrow \begin{gathered}\text { Day } 4 \\ \text { Bicuculline } \\ \text { or Vehicle }\end{gathered} \stackrel{\text { Day } 5}{\mathbf{2 0} \text { min }} \rightarrow$ Novel Taste $\rightarrow$ Choice Test

Figure 2. Local GABA $A_{A}$ receptor activity in the alC is upstream of muscarinic AChR-dependent reduction in QR2 mRNA levels. a, Rats were given a novel or familiar taste 20 min after having received injections of vehicle, bicuculline, or muscimol in the alC and were killed $3 \mathrm{~h}$ later. $\boldsymbol{b}, \mathrm{A}$ significant reduction of QR2 mRNA was measured in the alC of rats that received injections of a novel taste and vehicle in the alC. Animals that received bicuculline all showed a reduction in QR2 mRNA, while no reduction in QR2 mRNA was measured in animals receiving muscimol. *Main effect (treatment); \#effect within treatments. $\boldsymbol{c}$, Implanted cannula positions were validated following behavioral tests. $\boldsymbol{d}$, Rats received either scopolamine or vehicle and 40 min later received local alC infusion of bicuculline. After $20 \mathrm{~min}$, the animals were given a familiar taste and were killed $3 \mathrm{~h}$ later. e, Scopolamine prevents the local, bicuculline-dependent reduction in QR2 mRNA in rat alC. $\boldsymbol{f}$, Rats received injections of either bicuculline or vehicle locally to alC, and 20 min later were given a novel taste. The next day, the animals were given a choice test between the novel taste and water, and preference for the newly learned taste was measured. $\boldsymbol{g}$, Rats that received bicuculline had significantly better memory of the novel taste compared with controls. Data are shown as the mean \pm SEM. $\# p<0.05 ; * p<0.05 ; * * p<0.01$. See supporting data in Extended Data Figure 2-1.

We then aimed to see whether its induced expression following novel versus familiar taste consumption is controlled by upstream neurotransmitters (i.e., GABA $A_{A}$ mediated release of $A C h$ and $m A C h R$ activation), similar to QR2 (Fig. 2), as seen in rats. To do so, rats were injected intraperitoneally with either scopolamine or vehicle and were stereotaxically injected with bicuculline or vehicle into the alC. The rats then received a familiar taste and were killed $1 \mathrm{~h}$ later (Fig. $3 \mathrm{c}$ ). Animals that received bicuculline and vehicle showed a significant increase in 
a

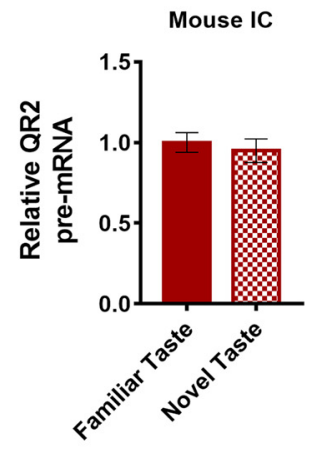

b

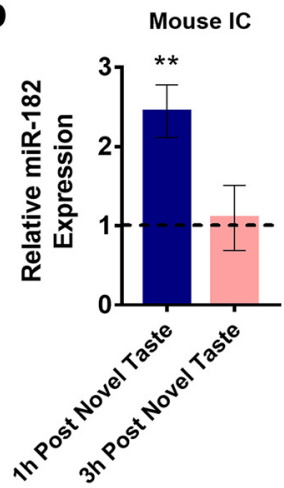

d

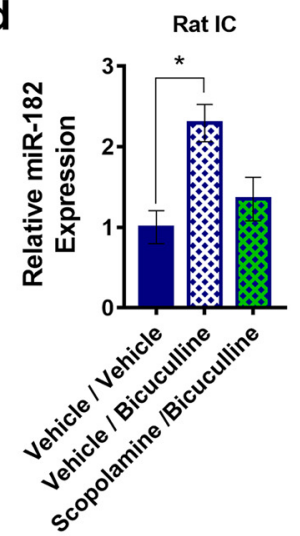

C

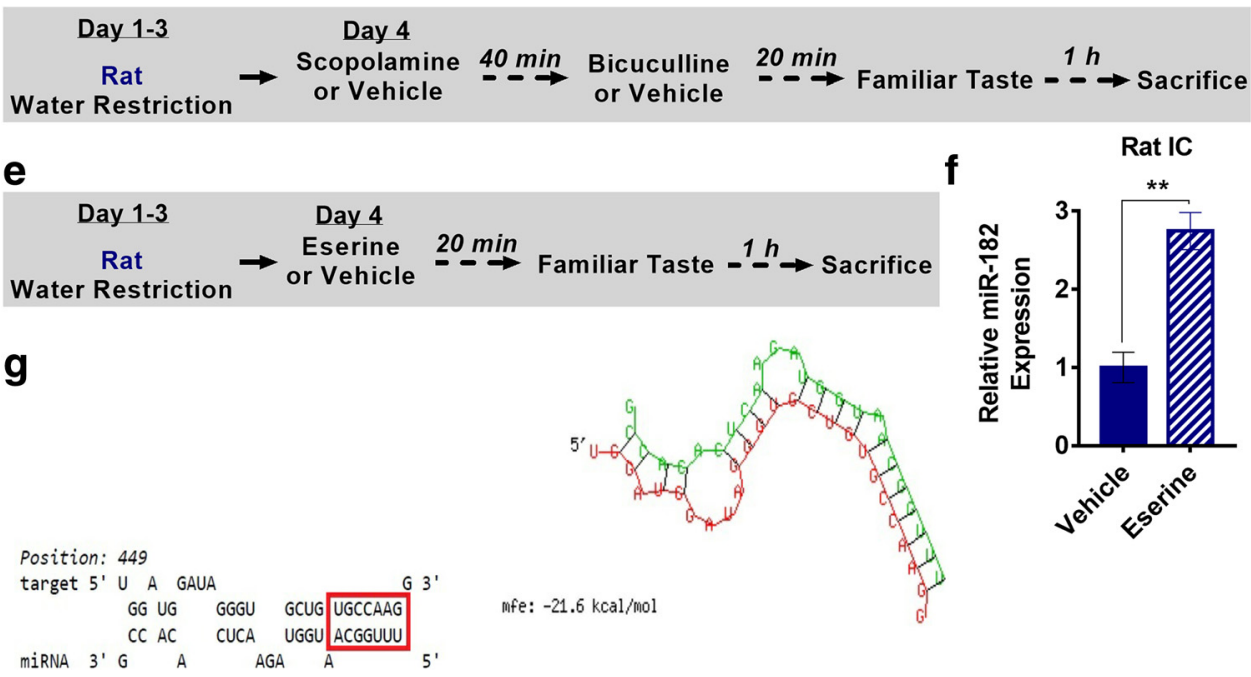

Figure 3. miR-182 is upregulated locally in the alC following novel taste consumption in a GABA $R$-mediated, muscarinic $A C h R$-dependent manner. $\boldsymbol{a}, \mathrm{QR} 2$ pre-mRNA levels were unchanged in the alC of mice following novel taste. $\boldsymbol{b}, \mathrm{miR}-182$ expression was measured 1 and $3 \mathrm{~h}$ following familiar or novel taste consumption in the alC of mice. miR-182 expression was elevated $1 \mathrm{~h}$, but not $3 \mathrm{~h}$, following novel taste. $\boldsymbol{c}$, Rats were given intraperitoneal injections of scopolamine or vehicle $1 \mathrm{~h}-$ and then alC infusions of vehicle or bicuculline 20 min-before familiar taste. Animals were killed $1 \mathrm{~h}$ later, and miR-182 was measured. $\boldsymbol{d}$, miR-182 expression was significantly increased in the alC after $1 \mathrm{~h}$, in rats that received bicuculline locally to the alC and vehicle intraperitoneally. $\boldsymbol{e}$, Infusions of vehicle or Eserine then were given locally to the alC of rats $20 \mathrm{~min}$ before familiar taste. Animals were killed $1 \mathrm{~h}$ later, and miR-182 was measured. $\boldsymbol{f}$, miR-182 expression significantly increased in rat alCs that received Eserine locally, compared with vehicle. $\boldsymbol{g}$, One of four predicted miR-182 seeds to QR2 mRNA binding sites (miR-182, green; QR2 mRNA, red) in the rat. Data are shown as the mean \pm SEM. $* p<0.05 ; * * p<0.01$. See supporting data in Extended Data Figure 3-1 and Extended Data Figure 3-2.

miR-182 in the alC compared with those that received the vehicle alone. However, scopolamine prevented this increase and kept miR-182 levels similar to those seen in control animals (Fig. $3 d$ ), suggesting that the increase in miR-182 levels is mediated by mAChR activation in the alC alone (Extended Data Fig. 3-1).

To assess whether local, alC-specific activation of mAChR would cause an increase in miR-182 levels (a mirror effect of scopolamine), the experiment was repeated with local infusion of Eserine, an ACh esterase inhibitor, which prolongs the innate effect of ACh. Namely, animals that were taught to drink from pipettes were then injected intracranially either with Eserine $(1 \mu \mathrm{g} / \mathrm{hemisphere})$ or vehicle 20 min before familiar taste presentation, and miR182 was measured $1 \mathrm{~h}$ following familiar taste consumption (Fig. 3e). Animals that received Eserine showed a significant increase in miR-182 levels, similar to those receiving bicuculline or a novel taste (Fig. 3f). With such closely tied paths for QR2 and miR-182 within the alC following novel taste consumption, $G A B A_{A} R$ modulation, and $\mathrm{mAChR}$ activation, we next examined whether miR182 hybridization to QR2 mRNA is predicted in silico. Using BiBiServ2 (Rehmsmeier et al., 2004), a number of miR-182 seed-to-QR2 mRNA hybridizations were identified in the mouse, rat, and human (Fig. 3g, Extended Data Fig. 3-2), placing miR-182 as a leading candidate for QR2 expression reduction following novel taste experience.

Increased miR-182 expression in the alC reduces local QR2 mRNA levels and improves novel taste learning

To test whether miR-182 can cause reduction in QR2 mRNA levels and enhance novel taste learning, we 
a

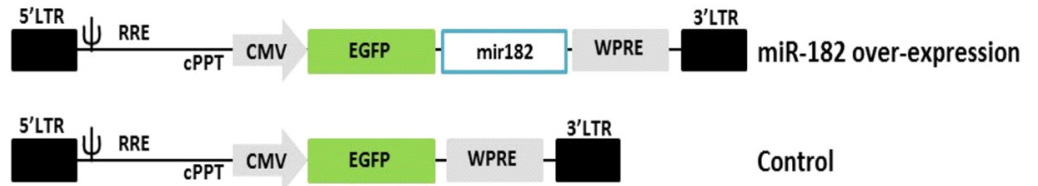

d

b

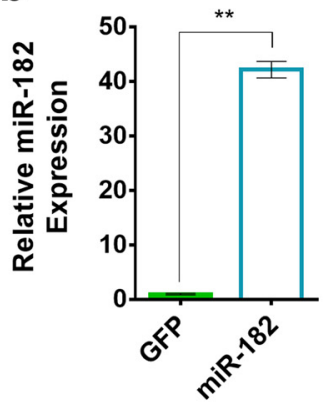

C

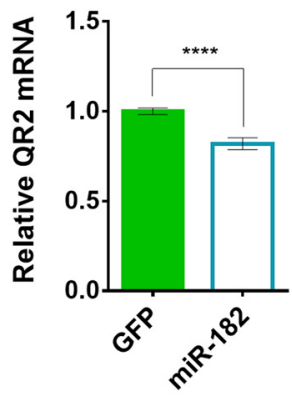

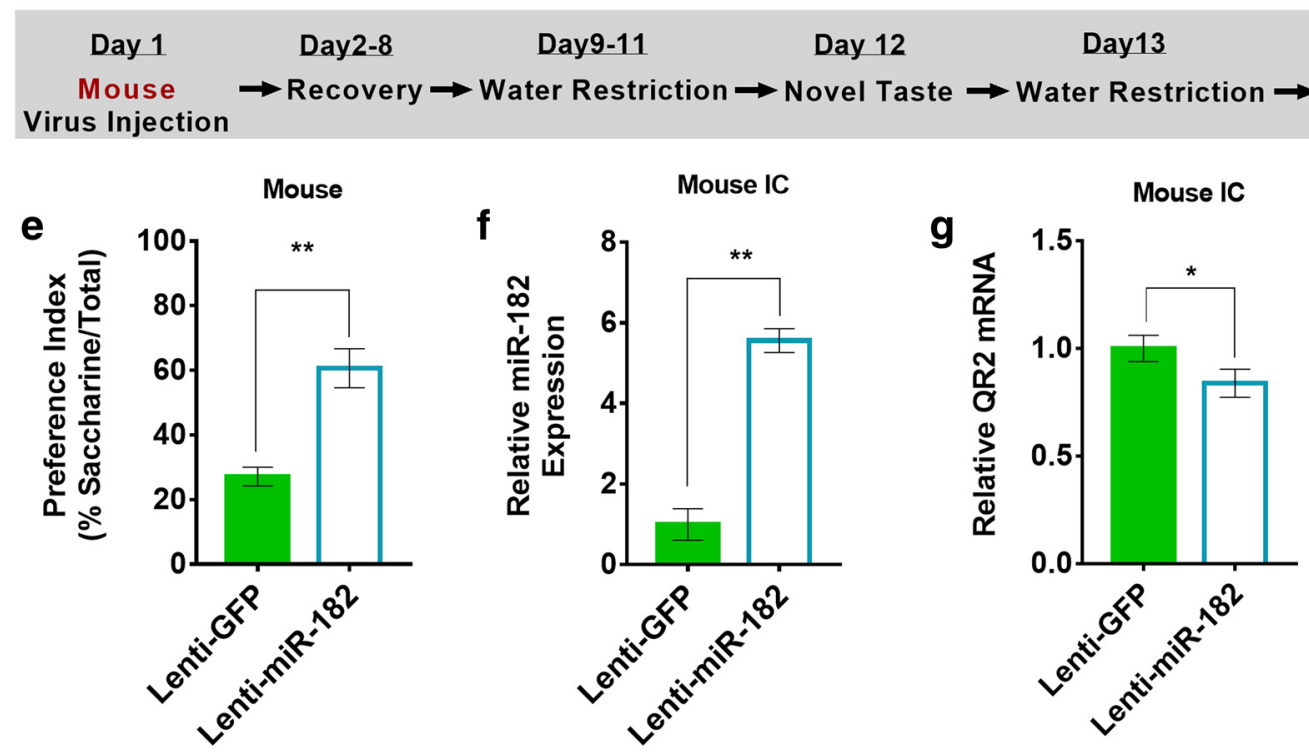

h

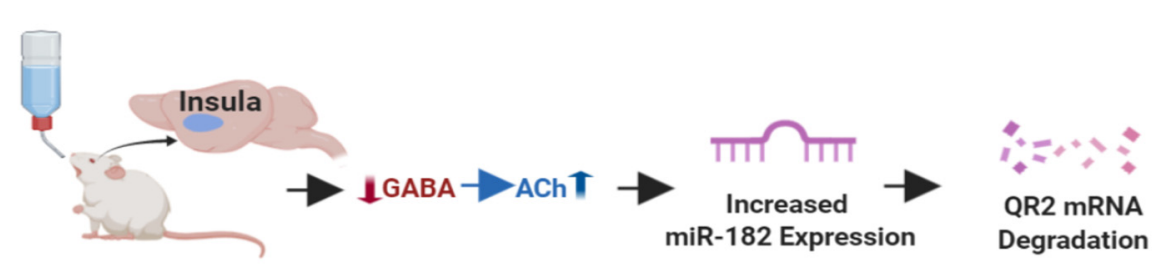

\section{Experiencing Novel}

Taste

Minutes Following

$1 \mathrm{~h}$ Later

$3 \mathrm{~h}$ Later

Day14

Day20

Choice Test $\rightarrow$ Sacrifice

Figure 4. Increased miR-182 expression in the alC reduces local QR2 mRNA levels and improves novel taste learning. a, Lentiviral vectors containing either reporter GFP and miR-182, or GFP alone, under the CMV promoter were generated. $\boldsymbol{b}$, Transfected HEK293FT cells showed significantly increased levels of miR-182 with the overexpression plasmid, compared with that of GFP. c, QR2 mRNA measured showed significantly reduced expression in cells transfected with the miR-182 plasmid. $\boldsymbol{d}$, Mice were injected with an miR-182 or GFP construct harboring lentivirus in the alC and then underwent novel taste learning, and were then given a choice test to assess taste memory. Mice were killed to assess infection efficacy. e, Mice injected with miR-182 showed significantly improved memory for the novel taste compared with GFP-injected controls. $\boldsymbol{f}$, alC samples taken from miR-182 overexpression vector-injected mice following completion of behavioral experiments show a significant increase in miR-182 expression compared with GFP-injected controls. $g$, QR2 mRNA was significantly reduced in the alC of mice injected with the miR-182 virus, compared with controls. $\boldsymbol{h}$, Schematic representation of the train of events on novel taste exposure, leading to reduced QR2 expression and improved novel taste memory in the rodent alC. Data are shown as the mean $\pm \mathrm{SEM} . * p<0.05 ; * * p<0.01 ; * * * p<0.001$; $* * * * p<0.0001$. See supporting data in Extended Data Figure 4-1.

synthesized constructs encoding miR-182 overexpression and GFP reporter or GFP reporter alone (Fig. 4a). First, we tested the effect of the constructs by transfection of HEK293FT cells, which are known to express QR2 (Geiger et al., 2012), and miR-182 and QR2 expression levels were measured (Fig. 4b,c). HEK293FT cells treated with miR-182encoding plasmids showed a significant reduction in QR2 mRNA expression levels compared with GFP controls. 
To assess the effect of miR-182 overexpression on novel taste memory and the ability to cause a reduction in QR2 mRNA expression levels in the brain, mice were stereotaxically injected into the alC with a lentivirus containing the miR-182 or GFP control constructs under the CMV promoter. The mice were then trained to drink from pipettes and were given a novel taste, and $2 \mathrm{~d}$ later they were given a choice test to measure the strength of the novel taste memory (Fig. 4d). The group injected with miR-182 showed significantly improved taste memory compared with controls, as indicated by the increased preference for the newly learned taste (Fig. 4e). Validation of the virus delivery and infection was done by measuring miR-182 expression levels a week later. The miR-182 group showed significantly elevated miR-182 expression levels in the alC compared with controls (Fig. 4f), elsewhere, not previously (hippocampus; Extended Data Fig. 4-1), which caused a significant reduction in QR2 mRNA in the alC only (Fig. 4g). Thus, the expression of miR-182 affects QR2 mRNA expression in the alC and improves novel taste memory. Overall, as described in Figure $4 h$, novel taste stimuli cause reduced $\mathrm{GABA}_{A} R$ activation, which leads to local and prolonged influx of ACh and activation of mAChR. In turn, miR-182 expression is increased, eventually leading to reduced QR2 expression, among its other known targets, thus improving the long-term persistence of the novel taste memory.

\section{Endogenous QR2 activity generates cellular ROS and affects Kv2.1 channel redox state}

The function of QR2 is poorly understood in cells and is unknown in neurons. To establish whether QR2 can catalyze reduction reactions endogenously in the brain, the previously described QR2 inhibitor S29434 was used (Ferry et al., 2010). To validate its efficacy, purified QR2 activity was measured with or without the inhibitor. In accordance with previous studies, significant reduction in QR2 activity was observed using $200 \mathrm{~nm} \mathrm{S29434}$ and 10 nм QR2 (Fig. 5a). To ensure that the closely related NQO1 is not affected by a similar dose of S29434, purified NQO1 activity was measured with 200 nм S29434, dicoumarol (NQO1 inhibitor; Timson, 2017), or vehicle.

S29434 did not affect NQO1 activity, which was significantly reduced by dicoumarol, its known inhibitor (Fig. $5 b)$. Both NQO1 and QR2 are expressed in the mouse brain, and both can use BNAH as a synthetic cofactor, enabling concomitant endogenous brain quinone reductase activity measurement. Mouse brain cytoplasm was thus incubated with BNAH (100 $\mu \mathrm{m})$ and S29434 (200 nM) or vehicle, and total reductase activity was measured. As seen in Figure $5 c$, BNAH was effectively oxidized by endogenous quinone reductases, whereas S29434 administration significantly diminished the catalysis of BNAH oxidation. These findings demonstrate that, in the mouse brain cytoplasm, QR2 is able to act on quinone substrates (either endogenous or exogenous), given a synthetic cofactor, and that this activity is sensitive to S29434.
A long-standing issue with QR2 is the lack of any known endogenous cofactors, except the possible existence of a NADH metabolite, NRH (Friedlos and Knox, 1992). To assess whether there are any endogenous small molecules that could serve as cofactors in the brain, mouse brain cytoplasm was filtered, resulting in a filtrate containing only molecules $\leq 3 \mathrm{kDa}$ in size. Pure QR2 can be added to this filtrate, along with the synthetic substrate menadione. Upon QR2 activity, menadione is reduced to menadiol, a process that can be detected using HPLC (Boutin et al., 2005; Extended Data Fig. 5-1). We therefore conducted this assay, using increasing doses of S29434. A clear enzymatic reaction curve was seen, which was effectively inhibited by S29434 in a dose-dependent manner (S29434 doses: $200 \mathrm{~nm}, 2 \mu \mathrm{m}$, and $20 \mu \mathrm{m}$; Fig. 5d), confirming the presence of endogenous QR2 cofactors in the mouse brain for the first time. Together, these data indicate that QR2 does act as a quinone reductase in the brain, which raises the question as to what outcome.

Previous reports indicate a potentially deleterious effect of QR2 activity (Cassagnes et al., 2015; Chen et al., 2017). We therefore aimed to test the effect of QR2 activity on cellular ROS. To achieve this, HEK293FT quinone reductase activity was elevated by the addition of BNAH, and the effect of NQO1 and QR2 was measured by the addition of either dicoumarol or S29434. Baseline ROS levels were significantly reduced by quinone reductase activation upon the addition of BNAH; however, this was reversed only by the inhibition of NQO1, but not of QR2 (Fig. $5 e)$. This raises the possibility that QR2 activity may have a net opposite effect on the redox outcome in relation to that of NQO1, possibly due to the differential substrate specificity (Zhao et al., 1997). To more closely assess the effect of QR2 activity on cellular ROS, HEK293FT cells were treated with increasing doses of S29434. A dosedependent decrease in ROS was measured (Fig. 5f), indicating that QR2 contributes to cellular ROS, which corroborates reports in other cellular models using QR2 inhibitors. We next tested whether QR2 activity affects the redox state in the brain. To do so, we measured the redox state of ion channels expressed on neuronal soma, which have been shown to be involved in cognitive function in an ACh-dependent manner (Mohapatra and Trimmer, 2006; Yu et al., 2016). A promising ion channel to focus on was the voltage-gated potassium channel Kv2.1, which forms oligomers via cysteine oxidation and disulfide bridge formation between the channels on the cell membrane, thereby affecting the proper function of the channel (Misonou et al., 2005). We therefore aimed to measure Kv2.1 oligomerization upon QR2 expression reduction.

Mice were injected to the alC with either shQR2 or a scrambled control lentivirus. Kv2.1 oligomerization was then measured by native gels and Western blot (Extended Data Fig. 5-2). A significant reduction in Kv2.1 clumping was observed in mice with genetically reduced QR2 expression, compared with scrambled controls (Fig. $5 g$ ). To examine whether QR2 inhibition by intraperitoneal injection of S29434 has a similar effect on Kv2.1 oligomerization, mice were injected with the inhibitor or vehicle and were killed $4 \mathrm{~h}$ later. Mice receiving S29434 also showed 

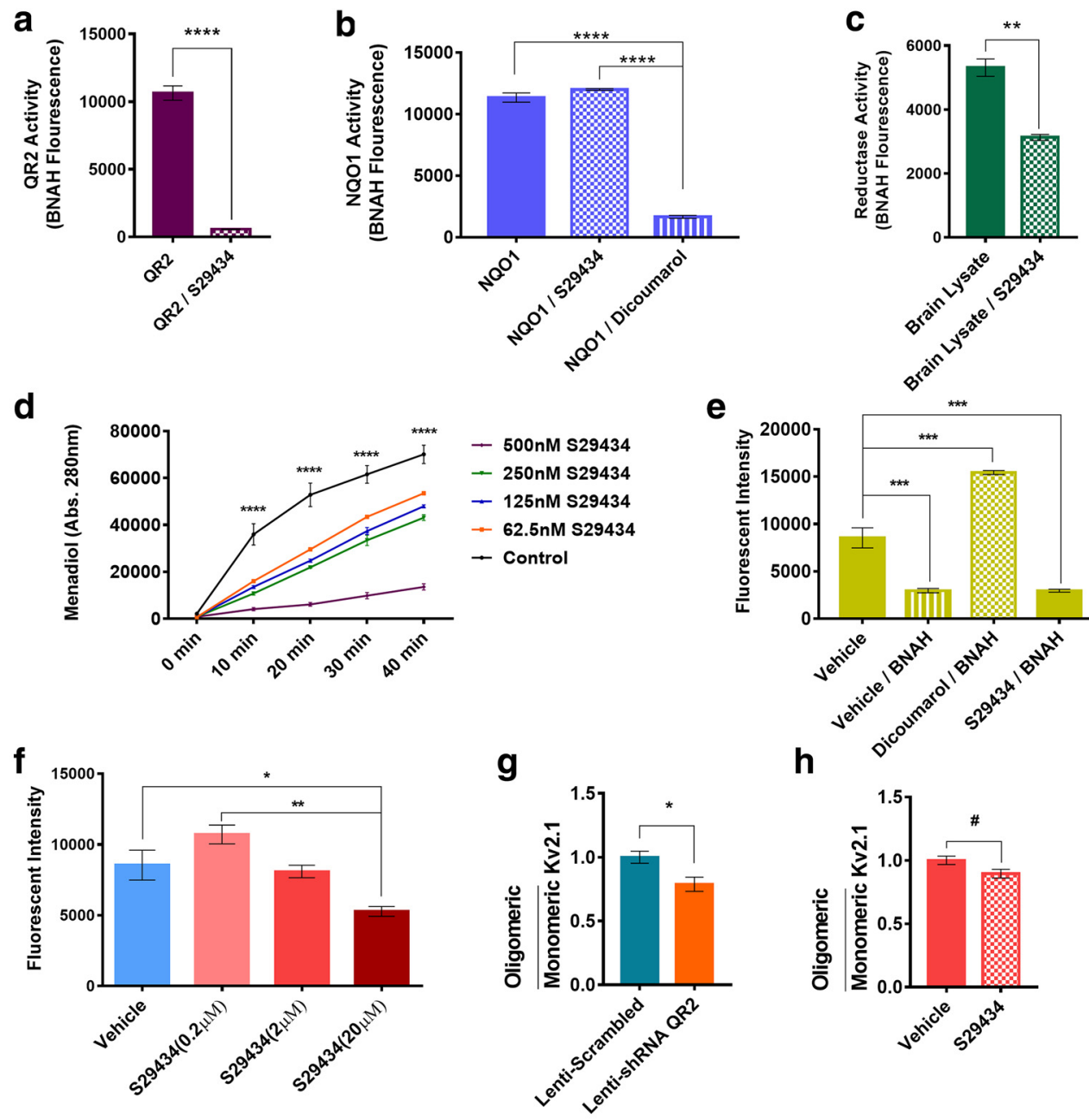

h
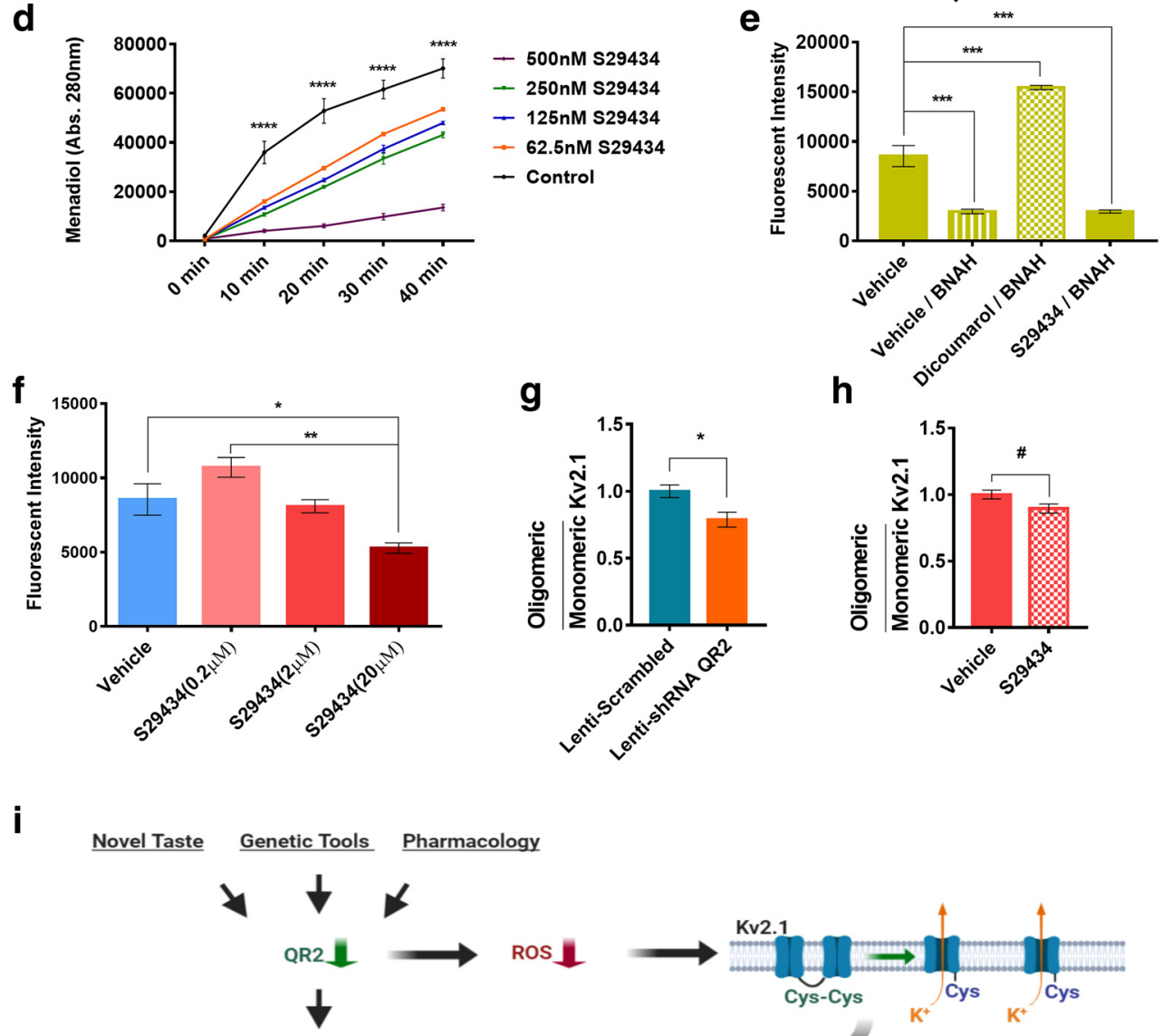

Enhanced Novel Taste Memory

Figure 5. Endogenous QR2 activity generates cellular ROS and affects Kv2.1 channel redox state. a, QR2 activity is strongly inhibited by S29434. $\boldsymbol{b}$, NQO1 activity is not affected by S29434, but is sensitive to dicoumarol. $\boldsymbol{c}$, Endogenous mouse brain NQO1 and QR2 activity can be measured with BNAH and is sensitive to QR2 inhibitor S29434. $\boldsymbol{d}$, QR2 uses small molecules of the mouse brain cytoplasm as cofactors to reduce menadione to menadiol in a S29434-sensitive manner. e, HEK293FT cells given reductase cofactor BNAH show reduction in the ROS signal, which is sensitive to dicoumarol, but not to S29434. $\boldsymbol{f}$, Basal ROS levels in HEK293FT cells are reduced by S29434 in a dose-dependent manner. g, Kv2.1 clumping in the mouse alC is significantly reduced by infection with shQR2 compared with scrambled control lentivirus. $\boldsymbol{h}$, Kv2.1 clumping in the mouse alC trends toward significant reduction by $\mathbf{S 2 9 4 3 4}$ compared with vehicle. $\boldsymbol{i}$, Schematic representation of the molecular events following QR2 downregulation. Upon reduced QR2 expression or activity, either naturally or experimentally, there is a reduction in cellular ROS. In the mouse brain, this is exemplified by the redox state of ROS-sensitive Kv2.1 potassium channels. Although Kv2.1 channels are likely not the only molecules affected by QR2 ROS modulation, functional Kv2.1 conductance has been shown to be important for proper memory formation. Data are shown as the mean \pm SEM. $\# p=0.05 ; * p<0.05 ; * * p<0.01 ; * * * p<0.001 ; * * * * p<0.0001$. See supporting data in Extended Data Figure 5-1 and Extended Data Figure 5-2.

a trend of reduced Kv2.1 oligomerization (Fig. 5h), albeit this was predictably less effective than local viral infection. Together, we show here that QR2 acts as a quinone reductase in the mouse brain, using endogenous small molecules as cofactors. The net effect of this QR2 activity contributes to cellular ROS, which are removed upon QR2 suppression in the alC, leading to the observed QR2-dependent stabilization of novel taste memory (Fig. 5i). 


\section{Discussion}

The current dogma of biological mechanisms underlying learning and memory proposes an active process where sensory information is converted to electrical activity. This activity enters the CNS and forms an internal representation of the world, which can in turn modify previous knowledge (Fernández and Morris, 2018). If the information is important according to evolutionary and developmental selection, this short-term memory trace can be stabilized to form a long-term memory to guide future behavior. These processes are mediated by a sequence of cellular and molecular events beginning with post-translation modifications, followed by proteostasis and gene expression programs enabling the consolidation and stabilization of a memory (Kandel et al., 2014). However, there is another possibility, where stabilization of memories involves the removal of an active constraint. In fact, there are many instances in biology where this strategy is used (e.g., kinase regulatory subunits, action potential thresholds). Here, we show that QR2 expression functions as such a removable memory constraint, describe its upstream mechanisms, and propose a mode of action.

Specifically, we found that QR2 expression is sensitive to local $\mathrm{GABA}_{A} R$ antagonism, unless $m A C h R$ s are antagonized beforehand, revealing a hierarchical, local relationship of GABA release downregulation $\rightarrow$ ACh release upregulation $\rightarrow$ activation of $\mathrm{mAChR} \rightarrow$ QR2 expression downregulation on novel taste stimuli (Fig. 2). Furthermore, we show that QR2 expression reduction is a major component of novel taste memory formation and consolidation. Being downstream of ACh, artificially removing QR2 is sufficient to form a long-term safe taste memory in the absence of ACh in the alC (Fig. 1). Such localized specificity of $\mathrm{QR} 2$ reduction in the alC by means of this disinhibitory circuit reveals QR2 as a central element of novel memory consolidation acting downstream of the known distal and local cellular activities during taste consumption. QR2 ultimately indicates novelty in this distinct sensory modality at the site of the taste memory per se (i.e., the $\mathrm{alC}$ ) and acts during the classic molecular consolidation phase. Furthermore, as identified in the study by Rappaport et al. (2015) and corroborated here, this occurs regardless of the taste itself or the associated palatability or aversion, but rather due to the novelty in and of itself. Thus, QR2 functions as a molecular "off" switch that enables the enhanced memory attained following an encounter of an animal with new incidental (i.e., nonassociative) information perceived as important. Local control of ACh release has been demonstrated in other cortical areas during various activities or stimuli as well (Giorgetti et al., 2000). Here, further evidence supporting local control of ACh by GABA sheds light on downstream outcomes of this form of local control of cholinergic modulation. This may indicate that ACh exerts its effects in two distinct phases during novel taste memory formation. The first phase is an immediate one, which occurs via known and well described mechanisms, such as the modulation of neuronal intrinsic properties, the enhancement of afferent input, and synaptic potentiation
(Hasselmo, 2006). The second phase, which we described here, is a lingering one, which is mediated by QR2 reduced expression. This may also explain the functionally prolonged local release of ACh seen in the alC following novel taste consumption (Shimura et al., 1995; Rodríguez-García and Miranda, 2016).

Unlike many other molecules involved in long-term memory formation, the reduction in QR2 mRNA expression levels occurs independently of changes in QR2 transcription (Fig. 3). Instead, QR2 mRNA is degraded following miR-182 upregulation upon novel taste consumption (Figs. 3, 4). The control of miR-182 and QR2 by the same GABA and ACh pathway, in an inverse and stepwise manner, first affecting miR-182 and subsequently affecting QR2, ties both in with the local disinhibitory GABA $R$ / $m A C h R$ circuit involved in novel taste memory (Fig. 3). This is an example of the effect of neuromodulation on gene expression, which defines a cortical state (Záborszky et al., 2018; La Camera et al., 2019). Furthermore, this establishes the importance of miR-182 in novel taste learning in the alC and identifies QR2 as a new target for this miR. The upstream control of $\mathrm{GABA}_{A} R$ and $m A C h R$ on miR-182 in the alC sheds further light on the mechanisms involved in its induction during long-term memory formation in the cortex. Intriguingly, previous studies have demonstrated the suppression of miR-182 cluster by protein phosphatase 1 (PP1) as a removable constraint on memory formation (Genoux et al., 2002; Woldemichael et al., 2016). The authors describe the reduced expression of miR-182 and the associated cognitive decline as reversible by overexpression of the miR-182 cluster (Jawaid et al., 2019), which is underexpressed during aberrant PP1 activity in aging and neurodegeneration. It is therefore possible that QR2 is placed further downstream as part of the effect of PP1mediated miR-182 regulation following novel taste stimulus in the alC (Adaikkan and Rosenblum, 2012).

Despite their structural similarity, QR2 (NQO2) and NQO1 cofactor and substrate affinity is distinctly different, and the inhibitor sensitivity of these two enzymes is equally dissimilar (Antoine et al., 2012). Since no endogenous QR2 cofactor has been confirmed, and previous studies have found varied outcomes of QR2 expression and activity, the function of QR2 remains unclear, especially in the brain, where less research has been done. Furthermore, a few studies have demonstrated the ability of QR2 to produce ROS instead of clearing them, via preferential reduction of orthoquinones, such as the quinone form of dopamine (Fu et al., 2008). Here, we confirm for the first time the presence of QR2 cofactors in the mouse brain, as well as QR2 activity in brain cytoplasm, which is sensitive to S29434 (Fig. 5). We therefore establish that QR2 is an active second quinone reductase in the mouse brain (in addition to NQO1), where there are endogenous small molecules serving as cofactors and substrates on which the enzyme is able to act.

Intriguingly, QR2 activity, as opposed to NQO1 (DinkovaKostova and Talalay, 2010), contributes to cellular ROS. There are many ROS generating and clearing enzymes in the brain that under normal physiological conditions have an important role in memory formation (Massaad and Klann, 
2011; Sies, 2017). The identification of QR2 as a removable mild ROS contributor and constraint on long-term memory consolidation raises the possibility that QR2 acts via redox modulation following taste novelty. This theory is supported by the decreased clumping of the Kv2.1 voltage-gated potassium channel seen in the mouse brain on QR2 removal (Fig. 5). When clumped, the conductance of Kv2.1 is altered, thus changing the intrinsic properties of neurons (Frazzini et al., 2016). This potentially deleterious phenomenon, which is correlated with memory decline, has been seen to increase in aged animals and in AD model mice (Patel and Sesti, 2016). In light of these data, it may be that QR2 is used to modulate redox to better facilitate transient high-plasticity states in neurons tagged for a memory trace. The oxidation of Kv2.1 represents only one important example of redox modulation in neurons that relates directly to memory (Bogeski and Niemeyer, 2014). However, this does not exclude the possibility that QR2 may affect many other redox-sensitive molecules, as it acts freely in the cytoplasm across the brain. Intriguingly, other well studied molecules that also reduce ROS and improve memory coincidentally inhibit QR2. Both melatonin (Boutin, 2016) and resveratrol (Buryanovskyy et al., 2004) are such molecules. However, it is yet unknown whether QR2 acts similarly in other brain regions in a manner that could explain in part the memory-improving and ROS-clearing effects of these molecules, as they have many other targets (Emet et al., 2016; Berman et al., 2017). Ultimately, it is necessary for further studies to establish the effect of QR2 in other brain regions during different learning modalities, and not just the alC following taste learning in male subjects.

QR2 is overexpressed in $A D$ brains Hashimoto and Nakai (2011). A major avenue toward tackling memory loss in $A D$ is a multimodal approach involving the targeting of ACh depletion and receptor activation by using ACh esterase inhibitors, ACh precursors, and ACh receptor agonists (Pepeu and Giovannini, 2010; Melancon et al., 2013). Another major avenue toward treating any neurodegenerative disease is reducing inflammation. A parsimonious route to reduce inflammation has been via the enhancement of the cholinergic system (Tabet, 2006). ACh esterase inhibitors and $\mathrm{mAChR}$ activation ameliorate inflammation in AD brains, while antagonism of the mAChR system is proinflammatory and maintains high QR2 levels (Fig. 1; Liu et al., 2017). It is therefore an intriguing possibility that QR2 may be at the crux of ACh downregulation and increased inflammation, acting as a potentially harmful reductase in cholinergically depleted cortical systems. Moreover, in our hands, the known cognitive enhancement of ACh esterase inhibitors can be explained by QR2-reduced expression in the cortex (Extended Data Fig. 4-1). Thus, our findings point to QR2 as a promising target for memory enhancement in health and disease.

\section{References}

Accolla R, Carleton A (2008) Internal body state influences topographical plasticity of sensory representations in the rat gustatory cortex. Proc Natl Acad Sci U S A 105:4010-4015.
Adaikkan C, Rosenblum K (2012) The role of protein phosphorylation in the gustatory cortex and amygdala during taste learning. Exp Neurobiol 21:37-51.

Alberini CM, Kandel ER (2014) The regulation of transcription in memory consolidation. Cold Spring Harb Perspect Biol 7: a021741.

Antoine M, Marcheteau E, Delagrange P, Ferry G, Boutin JA (2012) Characterization of cofactors, substrates and inhibitor binding to flavoenzyme quinone reductase 2 by automated supramolecular nano-electrospray ionization mass spectrometry. Int $\mathrm{J}$ Mass Spectrom 312:87-96.

Barry C, Heys JG, Hasselmo ME (2012) Possible role of acetylcholine in regulating spatial novelty effects on theta rhythm and grid cells. Front Neural Circuits 6:5.

Berman AY, Motechin RA, Wiesenfeld MY, Holz MK (2017) The therapeutic potential of resveratrol: a review of clinical trials. NPJ Precis Oncol 1:35.

Bogeski I, Niemeyer BA (2014) Redox regulation of ion channels. Antioxid Redox Signal 21:859-862.

Boutin JA (2016) Quinone reductase 2 as a promising target of melatonin therapeutic actions. Expert Opin Ther Targets 20:303-317.

Boutin JA, Chatelain-Egger F, Vella F, Delagrange P, Ferry G (2005) Quinone reductase 2 substrate specificity and inhibition pharmacology. Chem Biol Interact 151:213-228.

Buryanovskyy L, Fu Y, Boyd M, Ma Y, Hsieh T-C, Wu JM, Zhang Z (2004) Crystal structure of quinone reductase 2 in complex with resveratrol. Biochemistry 43:11417-11426.

Cassagnes LE, Perio P, Ferry G, Moulharat N, Antoine M, Gayon R, Boutin JA, Nepveu F, Reybier K (2015) In cellulo monitoring of quinone reductase activity and reactive oxygen species production during the redox cycling of 1,2 and 1,4 quinones. Free Radic Biol Med 89:126-134.

Cassagnes LE, Chhour M, Pério P, Sudor J, Gayon R, Ferry G, Boutin JA, Nepveu F, Reybier K (2018) Oxidative stress and neurodegeneration: the possible contribution of quinone reductase 2 . Free Radic Biol Med 120:56-61.

Chen D, Li X, Liu X, Liu X, Jiang X, Du J, Wang Q, Liang Y, Ma W (2017) NQO2 inhibition relieves reactive oxygen species effects on mouse oocyte meiotic maturation and embryo development. Biol Reprod 97:598-611.

Cotella D, Hernandez-Enriquez B, Wu X, Li R, Pan Z, Leveille J, Link CD, Oddo S, Sesti $F$ (2012) Toxic role of $\mathrm{K}^{+}$channel oxidation in mammalian brain. J Neurosci 32:4133-4144.

Dinkova-Kostova AT, Talalay P (2010) NAD(P)H:quinone acceptor oxidoreductase 1 (NQO1), a multifunctional antioxidant enzyme and exceptionally versatile cytoprotector. Arch Biochem Biophys 501:116-123.

Emet M, Ozcan H, Ozel L, Yayla M, Halici Z, Hacimuftuoglu A (2016) A review of melatonin, its receptors and drugs. Eurasian $\mathrm{J}$ Med 48:135-141.

Fernández G, Morris RGM (2018) Memory, novelty and prior knowledge. Trends Neurosci 41:654-659.

Ferry G, Hecht S, Berger S, Moulharat N, Coge F, Guillaumet G, Leclerc V, Yous S, Delagrange P, Boutin JA (2010) Old and new inhibitors of quinone reductase 2. Chem Biol Interact 186:103-109.

Franklin K, Paxinos G (2008) The mouse brain in stereotaxic coordinates. San Diego: Academic.

Frazzini V, Guarnieri S, Bomba M, Navarra R, Morabito C, Mariggiò MA, Sensi SL (2016) Altered Kv2.1 functioning promotes increased excitability in hippocampal neurons of an Alzheimer's disease mouse model. Cell Death Dis 7:e2100.

Friedlos F, Knox RJ (1992) Metabolism of nad(p)h by blood components. Biochem Pharmacol 44:631-635.

Frinchi M, Nuzzo D, Scaduto P, Di Carlo M, Massenti MF, Belluardo N, Mudò G (2019) Anti-inflammatory and antioxidant effects of muscarinic acetylcholine receptor (mAChR) activation in the rat hippocampus. Sci Rep 9:14233.

Fu Y, Buryanovskyy L, Zhang Z (2008) Quinone reductase 2 is a catechol quinone reductase. J Biol Chem 283:23829-23835. 
Gai Y, Liu Z, Cervantes-Sandoval I, Davis RL (2016) Drosophila SLC22A transporter is a memory suppressor gene that influences cholinergic neurotransmission to the mushroom bodies. Neuron 90:581-595.

Geiger T, Wehner A, Schaab C, Cox J, Mann M (2012) Comparative proteomic analysis of eleven common cell lines reveals ubiquitous but varying expression of most proteins. Mol Cell Proteomics 11: M111.014050.

Genoux D, Haditsch U, Knobloch M, Michalon A, Storm D, Mansuy IM (2002) Protein phosphatase 1 is a molecular constraint on learning and memory. Nature 418:970-975.

Giorgetti M, Bacciottini L, Giovannini MG, Colivicchi MA, Goldfarb J, Blandina P (2000) Local GABAergic modulation of acetylcholine release from the cortex of freely moving rats. Eur $\mathrm{J}$ Neurosci 12:1941-1948.

Gutiérrez R, Téllez LA, Bermúdez-Rattoni F (2003) Blockade of cortical muscarinic but not NMDA receptors prevents a novel taste from becoming familiar. Eur J Neurosci 17:1556-1562.

Hashimoto T, Nakai M (2011) Increased hippocampal quinone reductase 2 in Alzheimer's disease. Neurosci Lett 502:10-12.

Hasselmo ME (2006) The role of acetylcholine in learning and memory. Curr Opin Neurobiol 16:710-715

Hasselmo ME, McGaughy J (2004) High acetylcholine levels set circuit dynamics for attention and encoding and low acetylcholine levels set dynamics for consolidation. Prog Brain Res 145:207231.

Jawaid A, Woldemichael BT, Kremer EA, Laferriere F, Gaur N, Afroz T, Polymenidou M, Mansuy IM (2019) Memory decline and its reversal in aging and neurodegeneration involve miR-183/96/182 biogenesis. Mol Neurobiol 56:3451-3462.

Kandel ER, Dudai Y, Mayford MR (2014) The molecular and systems biology of memory. Cell 157:163-186.

Katz DB, Sadacca BF (2011) Taste. In: Neurobiology of sensation and reward (Katz DB, Sadacca BF, Gottfried JA, eds). Boca Raton, FL: CRC

La Camera G, Fontanini A, Mazzucato L (2019) Cortical computations via metastable activity. Curr Opin Neurobiol 58:37-45.

Lisman J, Cooper K, Sehgal M, Silva AJ (2018) Memory formation depends on both synapse-specific modifications of synaptic strength and cell-specific increases in excitability. Nat Neurosci 21:309-314

Liu W, Rabinovich A, Nash Y, Frenkel D, Wang Y, Youdim MBH, Weinreb O (2017) Anti-inflammatory and protective effects of MT031, a novel multitarget MAO-A and AChE/BuChE inhibitor in scopolamine mouse model and inflammatory cells. Neuropharmacology 113:445-456.

Massaad CA, Klann E (2011) Reactive oxygen species in the regulation of synaptic plasticity and memory. Antioxid Redox Signal 14:2013-2054.

Melancon BJ, Tarr JC, Panarese JD, Wood MR, Lindsley CW (2013) Allosteric modulation of the M1 muscarinic acetylcholine receptor: improving cognition and a potential treatment for schizophrenia and Alzheimer's disease. Drug Discov Today 18:1185-1199.

Merhav M, Rosenblum K (2008) Facilitation of taste memory acquisition by experiencing previous novel taste is protein-synthesis dependent. Learn Mem 15:501-507.

Miranda MI, Ferreira G, Ramírez-Lugo L, Bermúdez-Rattoni F (2003) Role of cholinergic system on the construction of memories: taste memory encoding. Neurobiol Learn Mem 80:211-222.

Misonou H, Mohapatra DP, Trimmer JS (2005) Kv2.1: a voltagegated $\mathrm{K}+$ channel critical to dynamic control of neuronal excitability. Neurotoxicology 26:743-752.

Mohapatra DP, Trimmer JS (2006) The Kv2.1 C terminus can autonomously transfer Kv2.1-like phosphorylation-dependent localization, voltage-dependent gating, and muscarinic modulation to diverse Kv channels. J Neurosci 26:685-695.
Patel R, Sesti F (2016) Oxidation of ion channels in the aging nervous system. Brain Res 1639:174-185.

Paxinos G, Watson C (2007) The rat brain in stereotaxic coordinates: hard cover edition. Amsterdam: Elsevier.

Pepeu G, Giovannini MG (2010) Cholinesterase inhibitors and memory. Chem Biol Interact 187:403-408.

Rappaport AN, Jacob E, Sharma V, Inberg S, Elkobi A, OunallahSaad H, Pasmanik-Chor M, Edry E, Rosenblum K (2015) Expression of quinone reductase-2 in the cortex is a muscarinic acetylcholine receptor-dependent memory consolidation constraint. J Neurosci 35:15568-15581.

Rehmsmeier M, Steffen P, Hochsmann M, Giegerich R (2004) Fast and effective prediction of microRNA/target duplexes. RNA 10: 1507-1517.

Rodríguez-García G, Miranda MI (2016) Opposing roles of cholinergic and GABAergic activity in the insular cortex and nucleus basalis magnocellularis during novel recognition and familiar taste memory retrieval. J Neurosci 36:1879-1889.

Rosenblum K, Meiri N, Dudai Y (1993) Taste memory: the role of protein synthesis in gustatory cortex. Behav Neural Biol 59:49-56.

Santini E, Huynh TN, Klann E (2014) Mechanisms of translation control underlying long-lasting synaptic plasticity and the consolidation of long-term memory. Prog Mol Biol Transl Sci 122:131-167.

Shimura T, Suzuki M, Yamamoto T (1995) Aversive taste stimuli facilitate extracellular acetylcholine release in the insular gustatory cortex of the rat: a microdialysis study. Brain Res 679:221-225.

Sies $H(2017)$ Hydrogen peroxide as a central redox signaling molecule in physiological oxidative stress: oxidative eustress. Redox Biol 11:613-619.

Stern E, Chinnakkaruppan A, David O, Sonenberg N, Rosenblum K (2013) Blocking the elF2 $\alpha$ kinase (PKR) enhances positive and negative forms of cortex-dependent taste memory. J Neurosci 33:2517-2525

Tabet N (2006) Acetylcholinesterase inhibitors for Alzheimer's disease: anti-inflammatories in acetylcholine clothing! Age Ageing 35:336-338.

Timson D (2017) Dicoumarol: a drug which hits at least two very different targets in vitamin K metabolism. Curr Drug Targets 18:500510.

Tiscornia G, Singer O, Verma IM (2006) Production and purification of lentiviral vectors. Nat Protoc 1:241-245.

Woldemichael BT, Mansuy IM (2016) Micro-RNAs in cognition and cognitive disorders: potential for novel biomarkers and therapeutics. Biochem Pharmacol 104:1-7.

Woldemichael BT, Jawaid A, Kremer EA, Gaur N, Krol J, Marchais A, Mansuy IM (2016) The microRNA cluster miR-183/96/182 contributes to long-term memory in a protein phosphatase 1-dependent manner. Nat Commun 7:12594.

Yiannakas A, Rosenblum K (2017) The insula and taste learning. Front Mol Neurosci 10:335.

Yu W, Parakramaweera R, Teng S, Gowda M, Sharad Y, ThakkerVaria S, Alder J, Sesti F (2016) Oxidation of KCNB1 potassium channels causes neurotoxicity and cognitive impairment in a mouse model of traumatic brain injury. J Neurosci 36:1108411096.

Záborszky L, Gombkoto P, Varsanyi P, Gielow MR, Poe G, Role LW, Ananth M, Rajebhosale P, Talmage DA, Hasselmo ME, Dannenberg H, Minces VH, Chiba AA (2018) Specific basal forebrain-cortical cholinergic circuits coordinate cognitive operations. J Neurosci 38:9446-9458.

Zhao Q, Yang XL, Holtzclaw WD, Talalay P (1997) Unexpected genetic and structural relationships of a long-forgotten flavoenzyme to $\mathrm{NAD}(\mathrm{P}) \mathrm{H}$ :quinone reductase (DT-diaphorase). Proc Natl Acad Sci U S A 94:1669-1674. 